\title{
Effects of climate change on environmental sustainability
}

\author{
Manuela Tvaronavičiene $\dot{1}^{1,2 *}$ \\ ${ }^{1}$ Vilnius Gediminas Technical University (Vilnius Tech), Sauletekio 11, 10223, Vilnius, Lithuania \\ ${ }^{2}$ General Jonas Zemaitis Military Academy of Lithuania, Silo 5A, 0322, Vilnius, Lithuania
}

\begin{abstract}
Adaptation strategies to the climate change include measures that can be taken to take account of the new climatic conditions. This paper aims at assessing the effects of climate change on environmental sustainability. This sustainability constitutes a major problem in many countries and regions around the world that experience industrial pollution, degradation of land as well as natural disasters caused by the global warming. The paper shows that adaptation strategies are often parallel strategies that can be integrated simultaneously with the management of natural resources. They can make resources more efficient and resilient to climate change. The paper shows that reducing the carbon footprint by more than 50 percent by 2030 and eliminating it by 2050 might be a viable solution how to tackle the climate change and support the environmental sustainability.
\end{abstract}

\section{Introduction}

In general terms, the strategies to mitigate the climate change can be narrowed down to two major areas: i) removing greenhouse gases (such as $\mathrm{CO}_{2}$ ) from the atmosphere, and ii) preparing the societies to the effects of the climate change $[1,2]$.

Moreover, biodiversity should be seen as an important ally in dealing with climate change, rather than being portrayed as a victim of climate change $[3,4]$. Protected areas with biodiversity that support the current and future climate can improve ecosystem services, including biodiversity, which is essential for mitigating climate change, such as food security, water quality and species protection $[5,6]$.

However, ecosystem-based solutions will be far from sufficient, and there is still a need to address the issue of fossil fuel emissions as a primary approach to mitigating climate change. Since the beginning of international climate efforts, they have focused primarily on reducing greenhouse gas emissions as a means of combating climate change, not on restoring biodiversity [7].

Where vulnerability is high, it can be extremely important to reduce risk in the short term even in the face of uncertainty, and where vulnerability to climate change is increasing, where it is not increasing to adapt. But climate change is much more than rising temperatures, and increasing climate variability will produce equal or greater impacts that need to be addressed. Many adaptation measures are part of an integrated mitigation - measures that reduce

\footnotetext{
*Corresponding author: manuela.tvaronaviciene@vilniustech.lt
} 
greenhouse gas emissions. Measures to adapt forests to future conditions can help to maintain or increase their capacity to capture carbon $[8,9]$.

Energy-efficient and environmentally friendly technologies that reduce emissions from electricity generation and transport, build compactly and use renewable energy sources such as wind, solar, geothermal, biomass, hydro or biomass energy. Greenhouse gases (GHG) contribute primarily to global warming because they capture heat in the atmosphere. Of all the anthropogenic greenhouse gases emitted in 2004, $56 \%$ came from carbon monoxide (CO), which is caused by the use of fossil fuels, while the second part came from $\mathrm{CO}_{2}$ from deforestation $(17 \%)[10,11]$.

This paper is structured as follows: Section 2 describes the links between the climate change and environmental sustainability. Section 3 focus on the anthropogenic activities and global warming. Section 4 focuses on the global climate change and the Environmental Vulnerability Index (EVI). Finally, Section 5 summarizes the findings and provides final conclusions and implications.

\section{Climate change and environmental sustainability}

The importance of the philosophy of sustainability that is being practised and implemented is becoming increasingly important for our communities as water resources, species and biodiversity decline. There is no doubt that urgent action is needed if we are to save the planet $[12,13]$.

Large temperature changes that have now became a reality on Earth will greatly accelerate other changes already underway in the climate system, such as changing precipitation patterns, increasing evaporation due to warming, and increasing temperature extremes [14]. It remains to be seen to what extent the extent of this development is reflected in elevated temperatures and extremes, but the fact that greenhouse gases influence aspects of the water cycle early on provides a strong argument for the role of greenhouse gas emissions in climate change [15]. Although GHG-induced warming was partially offset by a small amount of forced anthropogenic aerosol changes, temperatures will still rise over the next few decades. The models simulating changes in precipitation in the oceans are relatively robust, with moist regions becoming wetter and dry regions becoming drier, but not at the same rate. In addition, it appears that extreme rainfall levels in the oceans, such as in Greenland and Antarctica, are useful constraints on future changes, even if they apply to a relatively small part of the world's land area [16].

Evidence from high-resolution climate models suggests that the intensity of sub- daily extreme rainfall is likely to increase in the future, making the theoretically estimated decadence most likely in many regions. The representation of extreme precipitation has generally improved and confidence in model-based projections has increased. The range of $10-30 \mathrm{~km}$, which is typically used in climate change studies, is still too small to explicitly represent sub- daily local heavy rainfall events [17]. More recently, weather forecasts with explicit convection have been used to predict extreme weather events such as floods and droughts. In the following, we propose that the use of sub daily extreme precipitation events as proxies for climate change risks will make it particularly easy to identify climate and climate change risks in the context of weather forecasting. To further underline the importance of heat extremes, we need to stress the fact that urban land has been estimated to be a proxy for the risk of climate change associated with extreme rainfall events. As described above, the direction and extent of the observed relative changes in urban areas correspond to the underlying measures of global temperature and precipitation changes in integrative quantitative models of total annual precipitation (mean annual total precipitation) [18].

Sustainability in responding to climate change should not be an overarching strategy that affects people's actions and responsibilities. The good news about climate change is that we 
know what is causing it and how to stop it, but we must not lose sight of other deeper environmental sustainability problems, which also require action. Climate science is one of the most important areas of scientific research in the world today, and we still have a lot to learn to fully understand this crucial problem [19]. Due to that many people rightly focused on the existential threat posed by climate change. Climate change will continue for decades to come, and no major measures will be taken to limit warming. The economic and political problems behind this are caused by the rapid growth of developing countries and the huge investments made worldwide in fossil fuels and other forms of fossil fuel use. In the future, not only our societies and ecosystems will commit to a much warmer world, but we will too. Ecosystem management and restoration play an important role and offer benefits, but only when used in conjunction with reducing fossil-fuel emissions can we mitigate the effects of climate change. We are truly in uncharted waters and we are contributing to these challenges to the best of our knowledge. As human civilization faces challenges of decarbonization, global greenhouse gas concentrations in the atmosphere are likely to stabilize, but carbon dioxide is rising, and the warming that will accompany it will occur much faster than we are experiencing today [20].

Even moderate changes in the climate are likely to have dramatic and damaging consequences, which will almost certainly affect every corner of the world. Around $8 \%$ of climate change is already taking place and can be directly linked to this global phenomenon. Global stability is being compromised, with less stability accompanied by higher pressure on governments, and the risk of civil unrest and political instability in countries such as China, India, and Brazil rising [21]. Urbanization and rural development affect many areas of biodiversity, including the increased risk of forest fires and habitat loss for wildlife. Changes in coastal land use also affect the distribution of wealth, as coastal countries provide a significant share of the world's natural resources, such as oil, gas, and coal.

The health effects of climate change include climate-related diseases such as asthma, allergies, respiratory diseases and cancer. Thence, the effects of human health and environmental change on human health and the environment need to be considered [22]. It provides a framework for quantifying the effects of changing air, land and ocean temperatures and reducing anthropogenic uncertainties in terms of health outcomes. All of these helps to make decisions at the local, national and global levels on health, environmental sustainability, health care and other issues. There are forms of environmental degradation about which we need to learn more and take measures to reduce them. We must face the inevitable effects of climate change in order to minimise the negative effects on human health and the environment, as well as on the health of the human population.

\section{Anthropogenic activities and global warming}

In the last 100 years, the average surface temperature of the earth has risen by more than 2 degrees Celsius. During this period, global surface temperatures, sea level rise and ocean acidification have increased in particular [23]. With regard to that, some pose the question of whether climate change is caused by natural events or human activities, also known as anthropogenic climate change [24]. Humans influence the climate and the temperature of the earth by burning fossil fuels, cutting down rainforests and keeping farm animals. Advocates argue that rising greenhouse gases in the atmosphere are a direct result of fossil fuel burning, and that this increase is causing significant and increasingly serious climate change, including sea-level rise, ocean acidification, and global warming. In fact, humans have been burning fossil fuels for more than 2,000 years. The gases in the Earth's atmosphere act like a glass greenhouse that captures the heat of the sun and prevents it from reaching space again. Over time, enormous amounts of greenhouse gases have been added to what is naturally occurring in our atmosphere, increasing the greenhouse effect and global warming. Nevertheless, earth 
warming follows and correlates with rising $\mathrm{CO}_{2}$ emissions that can affect the climate, and correlates with the increase in global warming due to the burning of fossil fuels [25].

Generally, $\mathrm{CO}_{2}$ is the greenhouse gas most commonly produced by human activities and responsible for human-induced global warming and other forms of climate change. Some scientists believe that human activities are the main cause of climate change. Nevertheless, the impact that man is causing is much greater in the current climate change cycle. For this reason, our current inaction on climate change and our inaction on global warming may be due not to human activity but to natural events. However, the current warming phase is occurring faster than past events, and the planet's climate is changing much faster than in past phases of climate change. One version of this is that the timescales differ from the Millennium, and that recent global warming is therefore only a phase in the upswing. The fact is that man has released large amounts of $\mathrm{CO}_{2}$ by burning fossil fuels, and this is the main cause of recent global warming. It has become clear that humanity has caused most of the warming of the last century by releasing heat - the separation of gases commonly referred to as greenhouse gases into the force of modern life, such as carbon dioxide and methane [26].

However, the observed fingerprints of global warming exclude this argument, as natural cycles match these fingerprints. Natural circuits, for example, cannot explain why satellites measure less heat that escapes into space at the very wavelengths where $\mathrm{CO}_{2}$ is absorbed. We have heard that the $\mathrm{CO}_{2}$ emissions from human activities are low compared to those released into nature. The term "global warming" refers to the fact that the atmosphere is warming above the surface of the Earth. Global warming is a sign that the Earth has passed and will pass away in the future, and it is happening because greenhouse gas emissions are continuing to rise. In other words, the planet's climate will change even if atmospheric $\mathrm{CO}_{2}$ and other greenhouse gas emissions continue to rise as a result of human activities. Climate change is happening, it is largely caused by human activities, and it will have many serious and potentially harmful effects in the coming decades. The scientific evidence paints a clear picture: climate change is occurring at least in the last few decades and possibly for many decades to come $[27,28]$. This is because greenhouse gas emissions include carbon dioxide, the most important greenhouse gas, which has reached levels of concentration not seen on Earth for more than 400,000 years. These greenhouse gases act as a blanket, trapping the sun's heat at the Earth's surface and influencing the planet's climate system. The forces contributing to climate change include naturally occurring concentrations of greenhouse gases in the atmosphere and human activities. Greenhouse gases play a key role in keeping the planet warm enough to be inhabited, and greenhouse gas emissions from human activities (e.g. burning fossil fuels, oil and gas extraction, mining, agriculture) are a major cause of our rapidly changing climate. The records show that global warming, especially in recent decades, is occurring much faster than ever before and cannot be explained by natural causes alone. When we burn carbon-based materials, carbon dioxide is released by burning fossil fuels and absorbs heat and releases $\mathrm{CO} 2$ into the atmosphere.

\section{Global climate change and the Environmental Vulnerability Index}

The Global Environmental Vulnerability Index (EVI) is calculated and published by the global risk consultancy Maplecroft [29]. The new global ranking, which calculates the vulnerability of the world's largest and fastest-growing economies, including India, has found that they face significant risks to their populations, ecosystems, businesses, and environment. The Global Environment Vulnerabilities Index, a global assessment of national vulnerability to climate change, assesses 42 social, economic, and environmental factors to assess national vulnerabilities in three key areas [30]. Vulnerability mapping can include a combination of 
indicators selected for mapping and indicators that represent vulnerability within a given spatial unit. These indicators are integrated and the current assessment includes more than 1,000 indicators for each of the three key areas, as well as a number of other indicators. The physical component is represented by the number of hectares of vegetation and the presence of climate-related indicators - associated disasters and climate scenarios. The subsequent appearance of climate-sensitive diseases is also a physical component. This includes the increased burden of disease due to the frequency and severity of extreme weather events such as floods, droughts and forest fires. It brings together eight different populations that are disproportionately affected by the effects of climate change [31].

Mediterranean basin is a concrete example where the effects of climate change are quite obvious. There is an urgent need to identify and understand the factors that influence environmental vulnerability to climate change and to establish links between population trends and environmental health. The region is rich in natural resources and culture and a popular tourist destination with a population of more than 1.5 million and a high level of tourist activity. Low-altitude island communities are affected by rising sea levels, which are accompanied by a changing climate. At the basic level, economically weak communities are most likely to be ill - prepared for the effects of climate change because they lack the necessary financial resources. It is highly likely that they will be affected not only by the effects of rising sea levels, but also by dramatic changes in ecosystem services, including access to food [32].

Globally, climate change is affecting rural communities, which are heavily dependent on agriculture and natural resources for their livelihoods and access to food [33-36].

There are other non-climatic factors that also determine how much climate change will affect cities and countries. Measuring the future impacts of climate change can be a major challenge, as scientists' predictions of climate change cannot be completely accurate and many different factors come into play, such as rising temperatures, changes in precipitation and snow cover, and the effects of extreme weather events. It also seems necessary to weigh up what happens politically and socially in a region to see if a country can prepare for it. Many developing countries are also particularly vulnerable, because their livelihoods depend on natural resources $[37,38]$. Overall, the EVI is a numerical index that reflects the status of the environmental vulnerability of a country or region. Since then, it has focused more on environmental threats from the misuse of the natural resources such as land, water and soil, and on human environmental management, which includes fossil fuel use, deforestation, land use change, human health and pollution. It was also decided that the vulnerability index should be easy to compile and based on indicators that are useful for comparing countries that reflect the relative vulnerability of countries. For example, the Mediterranean basin is connected to the Atlantic and the Mediterranean, as well as other regions [39]. It is a highly heterogeneous region where natural and anthropogenic activities interact in a complex way with climate variability [40]. Adaptivity is the ability of a species to cope and survive with changing conditions. For this reason, it is time to formulate a vulnerability index for all the regions of the world.

\section{Conclusions}

Overall, it becomes clear that climate change, in conjunction with socio-economic conditions, can increase vulnerability in both developed and developing countries. This can threaten the environmental sustainability and lead to many adverse effects to the nature and fauna. Thence, it is very important to join the efforts in both types of these countries and to take some action regardless of the level of income or life standards. All people on Earth are equally influenced by the climate change no matter which part of the planet they live in. 
Broadly speaking, greenhouse gas emissions associated with transition risk fall under two main categories: mitigation activities and transition risks. Climate protection includes measures that can be taken to limit changes caused by human activities to the global climate. Research and science, which support climate protection, is trying to understand change itself and to improve the knowledge that underlies climate protection policy.

We must overcome climate change and address other critical challenges facing the planet. Given the scale of these challenges, which could take months or even years to resolve, the world cannot afford to pay attention to climate change or the broader issue of sustainability. This reality is accompanied by an increased risk of physical and economic dangers, and the only way to avoid them is to aggressively decarbonize the economy and everyday life.

\section{References}

1. D. Klenert, F. Funke, L. Mattauch, B. O'Callaghan, Environmental and Resource Economics, 76(4), 751-778 (2020)

2. O. Rueda, J. Mogollón, A. Tukker, L. Scherer, Global Environmental Change, 102238 (2021)

3. D. Brooks, E. Hoberg, W. Boeger, The Stockholm paradigm: climate change and emerging disease (2019)

4. L. Bevan, Energy Research \& Social Science, 69, 101580 (2020)

5. M. Gaglio, V. Aschonitis, L. Pieretti, L. Santos, E. Gissi, G. Castaldelli, F. Fano, Ecological Modelling, 403, 23-34 (2019)

6. N. Seddon, A. Chausson, P. Berry, C. Girardin, A. Smith, B. Turner, Philosophical Transactions of the Royal Society B, 375(1794), 20190120 (2020)

7. H. Chenet, J. Ryan-Collins, F. Van Lerven, Ecological Economics, 183, 106957 (2021)

8. A. Koutroulis, L. Papadimitriou, M. Grillakis, I. Tsanis, R. Warren, R. Betts. Global and Planetary Change, 175, 52-63 (2019)

9. M. Morecroft, S. Duffield, M. Harley, J. Pearce-Higgins, N. Stevens, O. Watts, J. Whitaker, Science, 366(6471), eaaw9256 (2019)

10. N. Lee, S. Kim, J. Lee, Journal of $\mathrm{CO}_{2}$ Utilization, 44, 101414 (2021)

11. A. Shahsavari, M. Akbari, Renewable and Sustainable Energy Reviews, 90, 275-291 (2018)

12. A. Wals, A. Benavot, European Journal of Education, 52(4), 404-413 (2017)

13. M. Smith, I. Smit, L. Swemmer, M. Mokhatla, S. Freitag, D. Roux, L. Dziba, Biological Conservation, 255, 108985 (2021)

14. D. Koll, T. Cronin, Proceedings of the National Academy of Sciences, 115(41), 10293 10298 (2018)

15. M. Abdollahbeigi, Journal of Chemical Reviews, 2(4), 292-308 (2020)

16. N. Golledge, Wiley Interdisciplinary Reviews: Climate Change, 11(2), e634 (2020)

17. J. Schwaab, E. Davin, P. Bebi, A. Duguay-Tetzlaff, L. Waser, M. Haeni, R. Meier, Scientific Reports, 10(1), 1-9 (2020)

18. S. Scheuer, D. Haase, M. Volk, PLoS ONE, 12(12), e0189451 (2017)

19. D. Coen, Climate in motion: Science, empire, and the problem of scale (2019)

20. S. Brakman, H. Garretsen, A. Van Witteloostuijn, Social Sciences \& Humanities Open, 2(1), 100034 (2020)

21. J. Warner, I. Boas, Environment and Planning C: Politics and Space, 37(8), 1471-1488 (2019)

22. J. Bell, C. Brown, K. Conlon, S. Herring, K. Kunkel, J. Lawrimore, G. Luber, C. Schrek, A. Smith, C. Uejio, Journal of the Air \& Waste Management Association, 68(4), 265$287(2018)$

23. A. King, D. Karoly, Environmental Research Letters, 12(11), 114031 (2017) 
24. G. Hoogendoorn, B. Sütterlin, M. Siegrist, Journal of Risk Research, 23(12), 1577-1589 (2020)

25. B. Ekwurzel, J. Boneham, M. Dalton, R. Heede, R. Mera, M. Allen, P. Frumhoff, Climatic Change, 144(4), 579-590 (2017)

26. D. Baldocchi, J. Penuelas, Global Change Biology, 25(4), 1191-1197 (2019)

27. S. Becken, B. Mackey, Journal of Air Transport Management, 63, 71-83 (2017)

28. J. Lynch, M. Cain, D. Frame, R. Pierrehumbert, Frontiers in Sustainable Food Systems, 4, 300 (2021)

29. Maplecroft, Climate Change Vulnerability Index, https://www.maplecroft.com/riskindices/climate-change-vulnerability-index (2021)

30. H. Edmonds, J. Lovell, C. Lovell, Ecological Indicators, 117, 106529 (2020)

31. C. Linares, J. Díaz, M. Negev, G. Martínez, R. Debono, S. Paz, Environmental Research, 182, 109107 (2020)

32. N. Donthu, A. Gustafsson, Journal of Business Research, 117, 284 (2020)

33. I. Elhassnaoui, Z. Moumen, M. Tvaronavičienè, M. Ouarani, M. Bendaoud, I. Serrari, I. Lahmidi, M.A.S. Wahba, A. Bouziane, D. Ouazar, M.D. Hasnaoui, Insights into Regional Development, 3(1), 80-103 (2021)

34. O. Eddelani, N.E. El Idrissi, S. Monni, Insights into Regional Development, 1(1), 6-18 (2019)

35. Z. Moumen, N.E.A. El Idrissi, M. Tvaronavičienė, A. Lahrach, Insights into Regional Development, 1(4), 301-317 (2019)

36. M.F. Faridi, M.M. Sulphey, Entrepreneurship and Sustainability Issues, 6(3), 1336-1345 (2019)

37. O. Wagdi, A. Hasaneen, Entrepreneurship and Sustainability Issues, 7(2), 962-976 (2019)

38. R. Akhmadeev, A. Redkin, N. Glubokova, O., Bykanova, L. Malakhova, A. Rogov, Entrepreneurship and Sustainability Issues, 7(2), 1149-1170 (2019)

39. T. Caloiero, S. Veltri, P. Caloiero, F. Frustaci, Water, 10(8), 1043 (2018)

40. C. Leduc, A. Pulido-Bosch, B. Remini, Hydrogeology Journal, 25(6), 1529-1547 (2017) 